Revista de Antropología Social

ISSN: $1131-558 \mathrm{X}$

https://dx.doi.org/10.5209/raso.65614

\title{
Articulación de lógicas y modos de sociabilidad económicos: un análisis a partir de cuatro experiencias de Economía social y solidaria en España
}

\author{
Gaël Carrero Gros ${ }^{1}$, Jesús Sanz Abad ${ }^{2}$
}

Recibido: 7 de febrero de 2019/Aceptado: 30 de abril de 2019

Resumen. En las últimas décadas ha aumentado el interés por la denominada Economía Social y Solidaria (ESS), tanto como paradigma como sector de la economía. Sin embargo, en los trabajos académicos realizados se observa una brecha entre la caracterización teórica que se desarrolla en torno al concepto de la ESS y sus principios, y la escasez de estudios de caso realizados, apoyados en una recogida de datos empírica que permita comprender cómo se consiguen -o no- materializar estos principios en la práctica del día a día. En este artículo proponemos problematizar esta cuestión a partir de una aproximación etnográfica a cuatro iniciativas económicas de distintos sectores que se autoidentifican como "prácticas de ESS". Estos casos nos permiten mostrar una diversidad de casuísticas que ponen de relieve la diversidad de lógicas y modos de sociabilidad que se articulan bajo estas prácticas, y, finalmente, el escenario de pluralidad económica que se refuerza y se crea en torno a la ESS.

Palabras clave: Economía social y solidaria; tensiones, articulación de lógicas y formas de sociabilidad económica; pluralidad económica; etnografía.

\section{[en] Articulation of economic logics and modes of sociability: an analysis based on four experiences of Social and Solidarity Economy in Spain}

\begin{abstract}
In recent decades, interest in the so-called Social and Solidarity Economy (SSE) -as a paradigm and as a sector of the economy- has increased. Nevertheless, the academic work carried out shows a gap between the theoretical characterisation developed around the concept of the SSE and its principles, and the limited number of case studies based on empirical data collection, which allows us to understand how these principles can be materialised - or not-in day-to-day practice. In this article we propose to problematize this question through an ethnographic approach to four economic initiatives from different sectors that self-identify as "SSE practices". These cases show a diversity of casuistics that highlight the diversity of logics and modes of sociability that are articulated under these practices, and finally, the scenario of economic plurality that is reinforced and created around the SSE.
\end{abstract}

Keywords: Social and solidarity economy; tensions, articulation of logics and forms of economic sociability; economic plurality; ethnography.

Sumario. 1. Introducción. 2. El estudio de la Economía Social y Solidaria: delimitación, estado de la cuestión y aproximaciones teóricas. 3. Las experiencias de Economía Social y Solidaria: notas metodológicas y estudios de caso. 3.1. La cooperativa Agresta. 3.2. La asociación El Rincón Lento. 3.3. La moneda social del Mercado Social de Madrid. 3.4. Fiare Banca Ética. 4. A modo de conclusión. 6. Referencias bibliográficas.

\footnotetext{
Universidad Autónoma de Madrid gael.carrero@uam.es

Universidad Complutense de Madrid jesusanz@cps.ucm.es
} 
Cómo citar: Carrero Gros, G.; Sanz Abad, J. (2019). Articulación de lógicas y modos de sociabilidad económicos: un análisis a partir de cuatro experiencias de Economía social y solidaria en España, en Revista de Antropología Social 28(2), 247-273.

\section{Introducción}

En los últimos años, y especialmente a partir de la crisis financiera de 2008, están aumentando los discursos críticos ante el funcionamiento del sistema económicofinanciero basado en la lógica capitalista. Muchos de estos discursos críticos invocan la necesidad de un cambio a partir de un proceso de "(re)moralización de la economía" ante la acentuación de la precariedad y la vulnerabilidad de amplias capas de la población que ha provocado el deterioro de las condiciones laborales, los procesos de privatización de los servicios públicos y la especulación permitida en dicho sistema.

En sintonía con estos discursos, se ha producido un notable crecimiento de iniciativas económicas que reclaman la necesidad de construir una economía más democrática, centrada en las personas y respetuosa con el medio ambiente. Es el caso, por ejemplo, de numerosas empresas asociativas y cooperativas, vinculadas al planteamiento del emprendimiento social o la empresa social, el comercio justo o las finanzas éticas; pero también de iniciativas como los bancos del tiempo, las monedas sociales o los grupos de consumo, que no están enfocadas a la generación de empleo, sino que buscan reforzar los vínculos comunitarios para la resolución de necesidades concretas. Muchas de estas propuestas se han situado dentro de la denominada Economía Social y Solidaria (ESS), que podemos definir como un paradigma económico y, también, como un sector de la economía.

El auge de la ESS -tanto en su expresión teórica como práctica- ha despertado igualmente un creciente interés de investigadores de diversas disciplinas, constituyéndose un campo de estudio en sí mismo en torno a ella. Sin embargo, a pesar de este creciente interés por la ESS en el ámbito académico, constatamos que buena parte de la literatura producida sobre esta temática tiene una orientación más bien política y prescriptiva, antes que analítica y crítica. En la mayoría de los trabajos realizados, se caracterizan los principales rasgos de este paradigma que constituye la ESS, y se destaca su "vocación transformadora". Sin embargo, se aborda muy poco el análisis de las particularidades de las experiencias prácticas concretas que se hacen llamar "de ESS" (sus formas, su historia, sus dilemas, etc.), así como de la relación con el contexto en el que se dan, y cómo este las determina o las afecta.

Partiendo del señalamiento de esta carencia, este artículo busca indagar sobre las posibilidades que la etnografía ofrece para el estudio de la ESS, principalmente en su expresión práctica, centrando el foco de nuestro análisis en las posibles tensiones surgidas entre los principios a los que se adhieren y guían estas iniciativas económicas que se definen como ESS (como la cooperación, la solidaridad o su carácter no lucrativo), su necesaria búsqueda de sostenibilidad económica, y el hecho de actuar en un contexto marcado por una lógica capitalista (basada en la acumulación y el lucro y un modo de sociabilidad económica individualista y competitivo).

Para desarrollar este planteamiento, a nivel teórico, traeremos a colación algunos de los debates y conceptos teórico-analíticos procedentes de la antropología económica, prestando especial atención a las nociones de "articulación” y "pluralidad 
económica" que se han trabajado desde esta. Y a partir de ello, seguidamente, planteamos el análisis de cuatro iniciativas que se asientan en el marco de la ESS y se encuadran en distintos ámbitos del ciclo económico (producción, distribución, consumo y financiación) con el fin de indagar en algunas de las tensiones y dilemas que encuentran en su acción cotidiana.

\section{El estudio de la Economía Social y Solidaria: delimitación, estado de la cuestión y aproximaciones teóricas}

Haciendo una breve revisión de las principales temáticas que se han abordado desde hace al menos dos décadas, podemos distinguir varias líneas de investigación que han convertido a la ESS en un área de estudio en sí misma. Una primera línea de trabajo se centra en la conceptualización y caracterización de los rasgos de la ESS y su delimitación histórico-política. En este ámbito encontramos tanto trabajos de carácter más teórico, dirigidos a delimitar y diferenciar la ESS respecto a otras nociones cercanas como la economía popular, la empresa social o el Tercer Sector (Pérez de Mendiguren, Etxezarreta, y Guridi, 2009; Poirier, 2014), como trabajos de carácter más empírico dedicados a realizar mapeos de las iniciativas de ESS existentes (Vaillancourt, 2010; Hespanha, Santos, da Silva et al., 2015; Pérez de Mendiguren, y Etxezarreta, 2015), a analizar su génesis y evolución histórica en diferentes territorios (Laville, 2000, 2004; Coraggio, 2012) o la relación entre la ESS, los movimientos sociales y la política institucional (Marques, 2011; Fernandez y Miró, 2016).

Cercano a este planteamiento, se encuentra también otro grupo de trabajos que abordan los distintos vínculos que se establecen entre la ESS y otros enfoques críticos de la economía, como son la economía feminista (Osorio, 2019; Verschuur, Guérin, y Hillenkamp, 2015), el movimiento cooperativista, o la economía ecológica y el estudio de los bienes comunes (Calle y Casadevante, 2015; Sabin, 2016) principalmente.

Una segunda línea de trabajos está centrada en cuestiones de tipo epistemológico relacionadas con el significado ampliado o alternativo de "lo económico" que se propone bajo la noción de "ESS" (Laville, 2009b; Caillé, 2009), y las particularidades que presentan algunas de las prácticas económicas que se asumen "de ESS" (Hespanha, 2009; Lucas dos Santos y Da Silva, 2014). Muchos de los trabajos de esta línea parten de una crítica a algunos de los postulados del enfoque neoclásico, y a su concepción de la economía como una esfera autónoma respecto al conjunto de la sociedad regida por sus propias leyes. Así, desde estos trabajos se critican las premisas utilitaristas de la elección racional, y el individualismo metodológico (que presupone el carácter atomístico del individuo), a partir del que se propone estudiar la economía apelando a un método deductivo, definiéndola como la agregación de comportamientos individuales en el mercado. En cambio, con el enfoque que se propone abordar "lo económico" desde estos estudios de la ESS, se reivindica la necesidad de entender la economía desde una perspectiva más amplia, y para ello se recuperan algunas nociones analíticas y debates propuestos desde el campo de la antropología económica (Laville, 2004; Coraggio, 2014).

En este sentido, se apela, por ejemplo, a una concepción más "sustantiva" de la economía -entendiéndola como un sector de la cultura-, frente a la visión más "formal" de la misma que describíamos antes - como modalidad de la conducta-. Con ello se enfatiza la necesidad de pensar estas "prácticas de ESS" a partir de la noción 
de "incrustación" propuesta por Polanyi (1976; 1983), y se recupera la idea de que en nuestro cotidiano coexisten una pluralidad de principios que dan lugar a diversas formas de integración económica (reciprocidad, redistribución e intercambio) que orientan la producción y los intercambios. Así, este planteamiento se conecta en estos estudios con la propuesta de la ESS, en tanto a través de esta se definirían lógicas económicas que van más allá de la lógica mercantil capitalista dominante, reconociéndose la ESS como un ejemplo de esta pluralidad y coexistencia de formas de integración económica posibles.

Otra de las nociones más utilizadas a las que se ha acudido para el estudio de la ESS ha sido la de "economía moral"3. Esta noción se ha popularizado en el estudio de numerosos fenómenos sociales por su gran potencial heurístico para llamar la atención sobre la vinculación existente entre los procesos socioeconómicos, las instituciones sociales y los códigos culturales imperantes. En el caso del estudio de la ESS este término ha sido utilizado para llamar la atención y analizar los afectos y valores que se movilizan bajo este tipo de prácticas económicas en un contexto particular y, más concretamente, para destacar cómo estas prácticas económicas se legitiman al presentarse como una forma de construcción de otro tipo de relaciones sociales (Narotzky, 2013; Rebón, Kasparian, y Hernández, 2015).

Finalmente, a partir de estos planteamientos identificamos otra línea de trabajos que se enfocan a una reflexión sobre el potencial transformador de estas iniciativas de ESS. Para algunos autores estas prácticas constituyen formas de producción e intercambio "alternativas" al capitalismo, con una potencialidad "emancipatoria" respecto a la lógica capitalista (De Sousa Santos y Rodriguez, 2011), e incluso ven en ellas la base de lo que podría ser una "sociedad postcapitalista" (Gibsom-Graham, 2011). Sin embargo, otros investigadores enfatizan las dificultades que encuentran estas iniciativas para generar relaciones económicas no-capitalistas, entendiendo que estas experiencias son más bien respuestas y espacios de lucha por la vida en los intersticios del sistema hegemónico capitalista, y señalando también cómo estas iniciativas pueden llegar a ser funcionales a dicho sistema (Alquezar, Homs, Morelló et al., 2014; Darbus, 2015).

En todo caso, y en el marco de este debate, compartimos la afirmación realizada por Narotzky (2010), quien destaca cómo muchos de estos trabajos prestan poca atención al contexto en el que se desarrollan estas prácticas de ESS. Con ello, se quiere señalar cómo muchos estudios sobre estas iniciativas adolecen de un análisis crítico o más detallado de la vinculación inevitablemente existente entre estas prácticas y el marco capitalista en el que se insertan. Es decir, que, en la mayor parte de análisis sobre las iniciativas de ESS, se desatiende el hecho de que estas prácticas se insertan en contextos de mercado, donde se imponen dinámicas empresariales de competencia, tendiéndose a presentar estos aspectos como "extraños que perturban una supuesta pureza de las experiencias solidarias" (Reygadas, Pozzio y Medina, 2015:115).

Por ello, creemos que es necesario desarrollar una aproximación que preste atención a las vivencias cotidianas y al contexto de actuación de estas prácticas de ESS, al menos por dos cuestiones. En primer lugar, porque previene del riesgo de ideali-

Se observa que la noción de "economía moral", propuesta en primer lugar por el historiador E.P.Thompson e introducida en la antropología por J.Scott, ha pasado de aplicarse inicialmente en el estudio del campesinado y de la clase obrera, a utilizarse en temáticas vinculadas al estudio de lo económico como la propiedad, los desahucios o la corrupción y los favores, e incluso se ha ampliado su utilización en el estudio de la migración, el asilo y el refugio o la producción de conocimiento científico (cf. Fassin, 2018; Fassin y Eideliman, 2012). 
zación que existe sobre este tipo de iniciativas, lo cual es especialmente necesario si se tiene en cuenta, como decíamos, que en numerosos estudios sobre la ESS se desarrolla una mirada más bien prescriptiva, más centrada en lo que "debería ser" que en lo "realmente existente" (Reygadas, 2011). Y, en segundo lugar, porque en el estudio de esta temática constatamos la existencia de un déficit entre la conceptualización teórica realizada y el análisis de las prácticas que nos permita concretar la forma en que estas iniciativas se desarrollan en el ámbito del mercado, y cómo finalmente hacen convivir distintas lógicas y modos de sociabilidad económicos en ellas.

En este estado de cosas, a nivel analítico nos parece útil recuperar conceptos como el de "articulación", propuesto por Meillassoux (1977), en su caso para describir el vínculo que se daba entre el modo de producción doméstico y el capitalismo, así como acudir a la noción de "pluralidad de bases económicas" propuesta por Godelier (1991) para enfatizar cómo una persona, grupo o unidad de trabajo participa en actividades que pueden basarse en relaciones de producción de distinta naturaleza y hasta aparentemente contradictorias. La utilidad de aplicar estos planteamientos al estudio de las experiencias de ESS viene dada por los inevitables y/o decididos desplazamientos e intersecciones continuas que creemos que se dan en estas prácticas entre lo que definimos aquí como diversas lógicas y modos de sociabilidad económicos (antes que modos de producción) ${ }^{4}$. De este modo, consideramos que entender cómo se da esta articulación puede acercarnos a una mejor comprensión de las prácticas concretas en las que se traduce la ESS, así como de la heterogeneidad de estas experiencias, tanto a nivel interno respecto a cada entidad, como a nivel externo respecto al sector en el que desarrolla su actividad.

En conclusión, con todo lo planteado hasta aquí queremos destacar especialmente la escasez de trabajos que se han hecho a nivel empírico y la necesidad de realizar más estudios que aborden esta diversidad de lógicas y modos de sociabilidad económica en las que observamos que se apoyan estas experiencias de ESS, así como que analicen cómo estas se insertan o consiguen diferenciarse en el marco del proceso de expansión capitalista. Siguiendo esta advertencia al lector, y con el fin de abrir y profundizar en esta vía de investigación, consideramos que la realización de estudios de caso, construidos a partir de un abordaje etnográfico, puede ser una muy buena herramienta metodológica para el estudio de las iniciativas que se identifican como ESS, en tanto nos permite ver y analizar cómo operan estas en el plano cotidiano, ponerlas en relación a su contexto y, a partir de ello, entender los dilemas, límites, y contradicciones a los que hacen frente en su apuesta.

\section{Las experiencias de Economía Social y Solidaria: notas metodológicas y estudios de caso}

Basándonos en el planteamiento expuesto anteriormente, proponemos detenernos a continuación en el análisis de cuatro iniciativas que se identifican como parte de la

\footnotetext{
Consideramos esta opción, en tanto que el término "modos de producción", como menciona y recuerda Dolors Comás (1998), apela a un planteamiento que ya fue criticado en el momento álgido de esta teoría (años 70-80) por ser excesivamente abstracto y determinista, y por alejarse demasiado de los grupos concretos y de las situaciones híbridas reales con las que confronta el análisis etnográfico. De igual modo, adoptamos este término por considerar que no existe evidencia empírica suficiente para delimitar claramente unos "modos de producción" respecto a otros.
} 
ESS dentro del marco territorial de España. Se trata de una experiencia asociativa -El Rincón Lento-, dedicada a la promoción del consumo responsable; una moneda social -El Boniato-, utilizada en el marco de una red alternativa de producción, distribución y consumo; una cooperativa de servicios -Agresta-, dedicada a la consultoría y gestión forestal; y una cooperativa de ahorro y crédito -Fiare-que se sitúa en el marco de las finanzas éticas.

Estas experiencias han sido seleccionadas buscando que sus características y los sectores en los que operan fuesen lo más diversos posibles. Todo ello, con el fin de recuperar una diversidad de casuísticas que permitan poner de manifiesto distintos ejemplos del tipo de oportunidades, límites, paradojas, situaciones de tensión o de contradicción a las que se enfrentan cotidianamente este tipo de proyectos. Luego, además, nos interesaba trabajar sobre ellos, en relación a las particularidades del intento de cada cual por mantener la coherencia con su discurso transformador -en relación a su definición como iniciativas de ESS- y su desarrollo en un contexto económico de mercado (dominado por la lógica de la acumulación capitalista y el modo de sociabilidad competitivo derivado de esta).

Para la construcción de los casos, hemos recurrido a la triangulación de datos procedentes de la realización de un ejercicio de observación participante en diferentes actividades vinculadas o desarrolladas por estas iniciativas, de entrevistas semiestructuradas realizadas con diferentes implicados en estas, así como del análisis documental realizado sobre diversos documentos tanto públicos (páginas web, vídeos online, etc.) como internos (documentos de trabajo, actas, presupuestos, etc.), cedidos para la presente investigación desde las mismas iniciativas.

\subsection{La cooperativa Agresta}

El primer caso que queremos tratar es el de la cooperativa Agresta, seleccionado en este artículo por operar en un sector donde existe poca presencia del mundo cooperativo, así como por su considerable tamaño (en relación a otras empresas de ESS) y su particular evolución histórica. Agresta nace en 1999 de un grupo de 10 estudiantes de Ingeniería de Montes que apuestan por crear una empresa cooperativa en el ámbito de la gestión y consultoría forestal desde los principios de la ESS, buscando desarrollar un modelo de empresa viable social, económica y medioambientalmente.

Durante los primeros años fue creciendo y ampliando su actividad con la creación de varias sedes territoriales. Hasta que, a partir de 2008, la crisis económica empezó a frenar su actividad hasta casi pararla en 2012, fundamentalmente por la drástica reducción de fondos procedentes de las administraciones públicas para la gestión de montes (que era su principal cliente ${ }^{5}$ ). Este hecho convierte el caso en una muestra de la inevitable relación de dependencia que se puede dar entre la ESS y el Estado, sobre todo en determinados sectores, $y$, por tanto, de cómo este último puede tener un papel decisivo para impulsar o limitar el desarrollo de las iniciativas de ESS en algunos sectores.

La crisis afectó profundamente a Agresta quedándose apenas sin trabajo en prácticamente todos los territorios, lo que llevó a la cooperativa a realizar varios recortes

\footnotetext{
En su caso, el dinero que reporta la gestión de montes de particulares es apenas simbólica en comparación con las administraciones públicas, e incluso en muchos de estos casos, se contrata un servicio porque el particular ha conseguido una subvención pública para ello.
} 
presupuestarios y, finalmente, a abrir un expediente de regulación de empleo temporal que dejó bajo mínimos las condiciones laborales de los socios y trabajadores ${ }^{6}$. En estas circunstancias, la cooperativa apostó por un proceso de reestructuración interna y una diversificación de sus actividades, centrándose a partir de entonces fundamentalmente en la investigación, el desarrollo tecnológico y la internacionalización. Cabe aquí tener en cuenta que este proceso de reestructuración fue posible en buena medida por las características particulares de su actividad-volcada en la producción de conocimiento-, y por el relativamente poco capital material inmovilizado que tenía, por el tipo de actividad que desarrollan, lo cual facilitó su adaptación.

Ya para 2014, el proceso de reestructuración que se habían propuesto y su apuesta por abrirse a proyectos internacionales de carácter competitivo (como los programas Horizonte 2020, los fondos FEDER, los Proyectos Life, o los Grupos Operativos que desarrollaron a partir de 2016) para hacer frente a la crisis, unido a un repunte de la inversión de los fondos públicos en la gestión forestal, hizo que la cooperativa consiguiera recuperarse, e incluso fortalecerse económicamente, habiendo conseguido ampliar sus nichos de mercado. Así, el proyecto siguió creciendo, y ya para 2018 Agresta contaba con un total 50 personas con 36 socias y 14 trabajadoras organizadas en grupos territoriales que consiguieron generar en total una facturación superior a 1,9 millones de euros.

Respecto a cómo se plasma en la práctica de esta entidad su apuesta por los principios de la ESS, el primer elemento que podemos destacar es la elección de la forma jurídica de cooperativa, que determina su funcionamiento participativo, horizontal y redistributivo entre sus socios y trabajadores. En este sentido, la empresa se basa en un modelo de gobernanza caracterizado por diferentes comisiones y estructuras que busca favorecer la participación de todos los miembros a diferentes niveles.

Desde la cooperativa se señala cómo fue precisamente este funcionamiento cooperativo y redistributivo lo que posibilitó dar una respuesta a las dificultades económicas por las que pasó a raíz de la crisis económica. En estas circunstancias, cuando la empresa se quedó prácticamente sin trabajo, se tomó la decisión de no despedir a gente y compartir los escasos ingresos que llegaban entre los diferentes territorios, sabiendo que algunos territorios daban beneficios y otros daban pérdidas. Lo cual nos muestra cómo los mecanismos de solidaridad y apoyo establecidos dotaron a esta empresa de un marcado carácter resiliente ante las dificultades externas; así como expresa la fuerte identificación que los trabajadores tenían con la empresa, viéndose cómo su mantenimiento se convirtió en una suerte de "militancia", pues, visto desde un criterio meramente económico, no parecía tener sentido continuar. Una de las cooperativistas de la entidad entrevistadas lo contaba así:

Algunos de los grupos territoriales frecuentemente han dado pérdidas, y son los que dan beneficios los que sustentan a los demás. [...] Agresta es más que Sevilla, más que Soria, es un conjunto de todas las sedes y de todo ese trabajo en potencialidad que haya. [...durante la crisis] no todas las sedes podían mantener su tensión productiva [...]. Yo creo que [durante la crisis] fue la época en la que más nos hemos cuidado [...], lo hemos dado todo. 6 La cooperativa pasó a asumir únicamente el 30\% de la jornada laboral de todas las personas, siendo el otro $70 \%$
cubierto por el subsidio de desempleo. 
Ahora bien, a raíz de esta restructuración, parece que el carácter cooperativo de Agresta pasó a un segundo plano, al menos a nivel discursivo, destacándose en adelante mucho más su relación con la investigación e innovación, tal como comenta la misma entrevistada.

Al final ves que el discurso muchas veces ya no aparece tanto 'la cooperativa' sino ' $\mathrm{I}+\mathrm{D}+\mathrm{i}$ '. Entonces al final ves que, para estar en un mundo de 'I+D+i', Agresta ese discurso lo ha interiorizado de una forma que algunas veces dices... 'el I+D+i' [con gestos que señalan amplitud] y 'el Coop' [con gestos que señalan algo pequeño].

Por otra parte, otro de los rasgos que en la práctica tratan de plasmar la coherencia de la empresa con los principios de la ESS es la casi nula desigualdad salarial establecida entre sus miembros (independientemente de la cualificación y la tarea que realizan en la entidad) ${ }^{7}$. Preguntada por esta cuestión, una de las cooperativistas señalaba lo siguiente:

Sí se ha planteado [establecer una diferencia salarial], pero [no hacerlo] es uno de los... voy a decir, pedestales de Agresta, [...] uno de los valores de Agresta, ¿no? de los que sacamos un poquito pecho, todos cobramos lo mismo, entonces costaría mucho cambiarlo.

Ahora bien, cabe señalar que esta escasa diferenciación salarial entre trabajadores se ve favorecida por el hecho de que casi todas las personas tienen un perfil profesional muy parecido, y son dos las personas de la empresa que no tienen formación superior. De hecho, fue precisamente la entrada de estas dos personas en la empresa lo que originó el debate sobre la diferenciación salarial y por lo que también más adelante, cuando entraron otros perfiles más vinculados a la investigación con más formación que los propios cooperativistas de base, se recordó este debate y se decidió mantener esta apuesta por la igualdad salarial. Este hecho nos habla de cierta resistencia a seguir las medidas de valor del trabajo que marca el mercado y de cómo se trata de hacer prevalecer ciertos principios éticos frente a las dinámicas del mercado. Así, lo señalaba una de las socias entrevistadas:

Ahí fue el gran debate, porque estas eran las dos primeras personas que entraban sin una ingeniería. [...] Era como el FP de antes, un FP forestal, para hacer inventario [...] Ahora son socias y cobran lo mismo. Se valoró que es tan importante que tu hagas este proyecto en el ordenador como que Molina [el capataz] vaya a señalar un bosque.

7 Desde Agresta se señala que existe únicamente una pequeña diferencia salarial entre los socios cooperativistas respecto a los trabajadores, y un complemento para las personas que asumen cargos de responsabilidad, de no más de $50 €$ en ambos casos. Luego también, en el caso de los capataces, mientras no son socios, existe una diferencia salarial, respecto a los ingenieros de montes, de entorno a un $15 \%$. Se puede señalar aquí, además, que durante el ERTE que sufrió la entidad, las personas trabajadoras conservaron su salario y las socias rebajaron su salario, cobrando menos estas últimas. 
Por otra parte, la empresa se caracteriza también por tener numerosas medidas vinculadas a la conciliación, como son la flexibilidad horaria, o una política de permisos de paternidad y maternidad que amplía la cobertura existente por ley cubriendo la cooperativa dos meses más del mínimo legal; y se prevé también reservar una bolsa de horas para acompañar a terceros en caso de enfermedad. Pero, más allá de su funcionamiento asambleario, la igualdad salarial o las políticas de conciliación que propone, la adhesión de la empresa a la ESS se plasma también en el compromiso de tener como proveedores a empresas que trabajan en esta misma línea de compromiso social y/o medioambiental (como son entidades cooperativas de energía renovable, de papelería sostenible o que suministran terminales de telefonía móvil con sello de fabricación responsable), así como en la pertenencia a diferentes redes de ESS (como REAS, Coop57 o COOPERAMA). Y esta participación en redes de ESS se potencia con una bolsa de horas estipuladas como tiempo de trabajo de la que pueden disponer los miembros de la cooperativa que deseen participar en estas, habiéndose creado un "grupo de trabajo de ESS" dentro de la entidad, que se encarga de gestionar esta participación.

Pero más allá de los rasgos formales y organizacionales que hacen que Agresta se identifique como una iniciativa de ESS, nos parece interesante detenernos en el debate producido en el marco de la entidad sobre cómo gestionar su crecimiento. Este debate nos muestra cómo -al menos en un plano aspiracional de la entidad- se identifican dos lógicas diferentes que tratan de articularse y equilibrarse.

En los últimos años, la estrategia de internacionalización de la entidad la ha conducido a una rápida expansión, en gran medida por la obtención de proyectos de financiación europea con cuantías cada vez más elevadas. Este hecho ha llevado a contratar a nuevos trabajadores sin tener claro que esto fuera una parte de la estrategia deseada. Tal como comentaba en una entrevista una de las socias, esto generaba una tensión para la entidad en tanto que, aunque se asume que es temporal ${ }^{8}$, consideraban que se había llegado a "una proporción no deseable entre gente socia y gente no socia"".

Este crecimiento ha generado un fuerte debate dentro de la entidad, y ha motivado incluso la creación de grupos de trabajo para plantear cómo abordar estos dilemas en sus próximas asambleas generales. Para algunos miembros el crecimiento es positivo en sí mismo por suponer una confirmación del éxito de la estrategia de reestructuración de la empresa. En cambio, otros miembros ven este proceso con más cautela, señalando la necesidad de abrir un debate estratégico sobre cómo esta lógica puede trastocar profundamente el funcionamiento cooperativo de la entidad. Este dilema aparecía en la entrevista a una de las socias de la cooperativa al hablar de una posible concesión de un proyecto europeo de $500.000 €$ al que estaban pensando concurrir.

Si nos dan ese proyecto Agresta cambia. ¡Ah! que va a cambiar. Sí, sí, Agresta cambia si nos dan un proyecto de un tercio de nuestra facturación. [...] ¿queremos

\footnotetext{
En dos años todas las trabajadoras y trabajadores en fase societaria han de pasar a ser socias de la cooperativa. Por esta misma razón se debatía también sobre la incorporación o no de doctorados con Ayudas Torres Quevedo para doctorados industriales, que se planteaba por el posible interés para Agresta de llevar a cabo un acercamiento a la universidad en el marco de su apuesta por la investigación y el desarrollo. Generaba tensión esta idea por el hecho de que estas becas duran tres años, y se enfrentan con su política de contratación, en tanto a los dos años se debería hacer socia de la entidad a las personas trabajadoras, pero no se tiene la seguridad de que Agresta por sí misma vaya a poder mantener esos salarios una vez que se dejen de financiar externamente.
} 
crecer y entonces asumimos, y nos metemos en esto proyectos'?, ¿o nos metemos en estos proyectos y nos vemos abocados a crecer? ¿cómo queremos crecer? entonces ahora mismo tenemos este dilema en la cooperativa: crecimiento ¿fin o medio?, ¿en base a qué?, 500.000 pavos! ¿nos metemos en un proyecto de esta envergadura? esto tiene que ir a la asamblea.

[En alusión al crecimiento] quiero tenerlo como variable en mi función de producción $[\ldots]$ para que no me venga impuesto $[. .$.$] y no que, por meterme en este nicho$ de mercado y en este proyecto de tantos mil euros, me vea abocado a contratar a gente [...] 33.000 personas se gestionan de una forma, y 50 de otra, [...] el modelo no es que se pierda, pero cambia.

Otro hecho vinculado a esta discusión sobre el crecimiento lo encontramos en la posición que adoptó la entidad frente a la creación de una cooperativa dedicada a la misma actividad profesional en su mismo entorno de trabajo. Ante esa situación, Agresta decidió apoyar a este proyecto en su proceso de arranque por considerar, como señalaba una trabajadora, que "mola que el modelo se replique, no que este se haga gigante". Lo que muestra cómo se busca distanciarse de, e incluso confrontar, tanto la lógica del crecimiento incesante a la que responde el modelo de empresa capitalista convencional, como de las dinámicas de competencia que se naturalizan bajo este modelo.

Por último, más allá de la cuestión sobre el crecimiento, encontramos también una tensión no resuelta que se da para algunos miembros, en relación a la incongruencia que supone trabajar con algunos de sus clientes por el tipo de actuaciones que conlleva trabajar con estos, si se atiende a la coherencia con los principios de la ESS a los que se adhiere la entidad.

También tenemos al Banco Mundial como cliente, o sea ahí queda eso... o sea que tenemos un montón de contradicciones." "[¿ese te duele?] pues sí, algunas veces sí $[\ldots]$ También te digo que no lo hacemos todo porque sí, porque ahora en este momento, lo de irnos a Ecuador a un proyecto, se ha preguntado. [...] Con plantaciones de soja... es que la plantación de soja luego... o sea que existe el debate.

En conclusión, el análisis del caso de Agresta presenta algunos ejemplos de cómo se traducen a prácticas concretas los principios de la ESS, así como muestra algunos de los límites, contradicciones y formas de articulación que se pueden dar entre distintas lógicas y modos de sociabilidad económicos en estas experiencias en relación a: las particularidades de su organización interna, el contexto en el que se inscriben y el sector de actividad concreto al que se dedican. Luego, además, en cuanto a las tensiones y debates existentes, en este caso podemos destacar la reflexión que se plantea sobre "cómo y para qué crecer" o, dicho de otra manera, sobre si "el crecimiento debe ser un medio o un fin en sí mismo", pensando sobre todo en los efectos que dicho crecimiento podría tener sobre el modelo de gobernanza de la organización. Por otro lado, el hecho de que buena parte de la facturación de esta cooperativa proceda de fondos públicos (nacionales o europeos) es una buena muestra de los límites exis- 
tentes en torno al potencial emancipador que puedan tener las iniciativas enmarcadas en la ESS y sobre todo en determinados sectores de actividad.

\subsection{La asociación El Rincón Lento}

El Rincón Lento es una iniciativa que nace en 2009 en la ciudad de Guadalajara (España). Esta asociación recoge entre las líneas de actuación de sus estatutos la promoción de la ESS y el consumo responsable, aunque la entidad no está vinculada a ninguna red de este ámbito. Su actividad se basa en la gestión de un local multiespacio, que cuenta con una tienda dedicada al consumo responsable (venta de comercio justo, alimentos locales y ecológicos, artesanía y otros productos vinculados a proyectos de ESS) y con un espacio polivalente dedicado a la realización de exposiciones, talleres, cursos y otras actividades.

El Rincón Lento ha tenido un fuerte crecimiento desde su fundación, pasando de las 30 personas en sus inicios, a los 495 socios y 3 trabajadores con los que contaba a finales de 2018. Además, la entidad tiene una gran actividad, como lo demuestran las 316 actividades realizadas (como charlas, talleres y otros eventos) en el año 2017. A este hecho hay que sumar otras iniciativas, como la creación de una editorial propia y una moneda social, la promoción de diversos grupos de trabajo (sobre educación, feminismo o derechos humanos), o el apoyo a diversos emprendimientos sociales iniciados por miembros de la asociación. Todo ello apelando continuamente al carácter transformador que busca la iniciativa, como comenta una de sus trabajadoras ${ }^{10}$ :

Buscamos la transformación social. Buscamos cambio social. Queremos provocar cambios en Guadalajara tanto en pensamiento como en propuestas como de gente empoderada que busca tomar las riendas de su vida, de su ocio, de su consumo e intentar pegarle una vuelta a todo lo que no le parece justo.

A nivel económico, sus principales fuentes de financiación son las cuotas de so$\operatorname{cios}^{11}$, las ventas de la tienda y el cobro de algunas actividades propias ofertadas en el espacio. Además, la entidad ha recibido alguna subvención puntual por parte de las administraciones por alguna actividad realizada, si bien rara vez ha llegado a suponer más del $5 \%$ del presupuesto. Dentro del proyecto, la tienda dota al proyecto de liquidez y permite buena parte de su sostenibilidad económica, mientras que la organización de actividades en el espacio fomenta la socialización entre los socios y hace de él un punto de encuentro, a la par que permite dar a conocer la asociación, y establecer lazos y colaboraciones con otras entidades y colectivos del entorno. Precisamente, este carácter híbrido y complementario entre su actividad económica y su actividad social es una de las cuestiones que nos parecía más relevante destacar de este caso, aunque en el terreno discursivo llama la atención cómo la iniciativa suele presentarse más bien como "local multiespacio" o "laboratorio ciudadano experimental", dejando diluida su actividad comercial.

\footnotetext{
10 Ver en charla de Ana Ongil en TEDxAlcarriaSt. Disponible en: https:/www.youtube.com/watch?v=nYO5V6HeCwo

11 Los socios pagan 40 euros (si se trata de socios individuales) y 60 euros anuales (si se trata de una "unidad de convivencia").
} 
Para el debate que proponemos, queremos destacar cómo este buscado equilibrio -entre la actividad de la tienda y la finalidad social del proyecto- en la práctica no está libre de tensiones, como se ve, por ejemplo, en la falta de liquidez constante o en el cruce de las distintas lógicas que determinan el uso que se hace del espacio. La búsqueda de este equilibrio se observa bien en relación a la gestión de la tienda y al tipo de actividades que se decide programar en el espacio. Así, por ejemplo, al analizar las cuentas de la asociación, se observa cómo la tienda es central para la sostenibilidad económica del proyecto y que su gestión y mantenimiento ocupa la mayor parte del tiempo de los empleados y de buena parte del voluntariado realizado por los socios. Pero aun así, se constata que el equilibrio económico del proyecto ${ }^{12}$ solo se obtiene gracias a las aportaciones procedentes de otras actividades $\mathrm{y}$, especialmente, de las cuotas y aportaciones de $\operatorname{los} \operatorname{socios}^{13}$.

Por otro lado, en relación a la búsqueda de este equilibrio, cabe destacar que la actividad comercial que se desarrolla en la tienda tiene algunas limitaciones derivadas del uso polivalente que se da al espacio y de la finalidad social que caracteriza al proyecto. Por ejemplo, la entidad ha desechado introducir productos a granel que aumentarían los márgenes de ganancia, por considerar que su presencia no es compatible, por cuestiones de salubridad, con la actividad del espacio; y, por otro lado, no tiene productos que necesiten refrigeración, por suponer más dificultad para su gestión. De igual forma, desde la asociación se han rechazado también algunas actividades que podían aportaban ingresos, por considerarse que no tenían utilidad social o iban en contra de la "filosofía" del proyecto.

Ahora bien, al contrario, también existen algunos límites a esta subordinación de la actividad económica al carácter social del proyecto. Por ejemplo, se han dejado de pedir algunos productos vinculados a iniciativas sociales por tener poca salida en la tienda, o se han puesto muchos límites a la posibilidad de pagar algunos productos de la tienda en la moneda social -llamada La Bellota-que se ha impulsado desde el espacio, argumentando que "los trabajadores y las facturas las tenemos que pagar en euros y no en bellotas". Además, las bajas inversiones realizadas en la tienda en mobiliario o en publicidad, así como la no introducción de productos que tienen más difícil salida aunque aporten más margen de beneficio (como sucede con los libros o con algunos productos textiles), muestra cómo la estrategia de ventas seguida suele basarse en minimizar riesgos económicos y garantizar el abastecimiento de productos que tengan una fácil y rápida salida, sabiendo que esto limita en algunos casos el fin social que se busca cumplir en el espacio.

De este modo, se puede afirmar que la tienda es vista más como un medio para la difusión del "consumo responsable" y para financiar el proyecto, que como un fin en sí mismo. Prueba de ello es que en una jornada de reflexión numerosos socios, al debatir sobre el sentido del proyecto, señalaban que "no querían ser una tienda", y apostaban por potenciar la actividad social y diversificar las fuentes de ingreso como estrategia para garantizar la sostenibilidad económica del proyecto.

12 Hay que destacar que lo que se define como "equilibrio económico" es visto como la racionalidad económica deseable para el proyecto. Como gráficamente comentaba una trabajadora del espacio: "Somos una asociación sin ánimo de lucro, pero también sin ánimo de perdida”.

13 Analizando los balances de ingresos y gastos de la asociación se puede observar que las aportaciones de los socios suponen cerca de 16000 euros de ingresos para la entidad, cantidad que es fundamental para poder llegar al equilibrio presupuestario. 
Por otro lado, para comprender la lógica de funcionamiento del proyecto y asegurar su viabilidad económica, resulta fundamental entender el papel que tienen los socios en él. Los ejemplos en este sentido son múltiples. En 2014, se decidió cambiar de local a otro mucho más grande y fueron los socios quienes costearon las obras de acondicionamiento del nuevo local (valoradas en 28.000€) a través de la emisión de "bonos de apoyo" al proyecto, sin recurrir a crédito financiero. También es frecuente la realización de tareas de voluntariado por parte de los socios en la tienda, la realización de "pagos a cuenta" (pagos que hacen los socios por adelantado para adquirir posteriormente productos en la tienda y evitar posibles tensiones de liquidez), o la compra por adelantado de productos a través de pedidos conjuntos, que además de abastecer a la tienda de género, al tener una rápida salida permiten minimizar los riesgos de la actividad comercial.

En esta misma línea, la compra de productos en el local, aunque los socios a cambio reciben un descuento, es presentada en ocasiones como una suerte de "militancia económica", pues supone un soporte fundamental para la viabilidad y sostenibilidad del proyecto. Pero toda esta colaboración con el espacio, debe también ponerse en relación con el hecho de que, en sentido inverso, desde la entidad se proponen continuamente actividades (como campamentos, excursiones, talleres o fiestas, entre otras), que promueven la sociabilidad entre los socios, la identificación y adhesión de estos con el proyecto.

En relación a esta gestión de la base social del proyecto, cabe decir que este también es un factor fundamental que afecta a la compleja búsqueda de equilibrios que mencionábamos antes, por el carácter plural y diverso de la asociación. Este hecho se ve, por ejemplo, en el especial cuidado que se tiene a la hora de decidir si se cede o no el espacio para la realización de algunas actividades que podría tener detractores entre los socios, como de hecho sucedió con la denegación del uso del espacio para la realización de reuniones de un partido político, o con los debates sobre la adhesión o no a algunas convocatorias sociales bajo el argumento de que "el Rincón Lento es un proyecto plural".

En resumen, El Rincón Lento se presenta como un caso interesante para reflexionar sobre las tensiones, las contradicciones y las formas de articulación que se dan entre las dos lógicas que se entrecruzan en este espacio. Esto es, en torno al equilibrio que se busca establecer entre su vocación para servir de espacio de promoción de iniciativas sociales que busquen la transformación social, por un lado; y, por otro, la actividad comercial que se lleva a cabo para garantizar la sostenibilidad económica del proyecto. De la misma forma, esta experiencia nos ilustra sobre la importancia que pueden tener para la sustentabilidad de los proyectos de ESS, la identificación y el compromiso mantenidos por los socios y trabajadores hacia estos espacios, ya que, como puede verse, es precisamente esta identificación la que le da su razón de ser al proyecto y lo dota de un fuerte carácter autogestionario, además de garantizar su autonomía económica.

\subsection{La moneda social del Mercado Social de Madrid}

Otra de las iniciativas interesantes a analizar en relación al debate que estamos presentando aquí son las «monedas sociales». Las monedas sociales se pueden describir como sistemas de intercambio de bienes, servicios o saberes, cuyo fin es facilitar la creación de sistemas de intercambio local propios con el fin de relocalizar y privile- 
giar la producción y el consumo local (Blanc, 2011; Corrons, 2015). Sus defensores señalan que ayudan a generar vínculos sociales y a crear un nuevo tejido económico local, convirtiéndose en un instrumento útil para luchar contra la pobreza, al crear medios adicionales para adquirir bienes y permitir integrar a personas desempleadas en una lógica de intercambio que valoriza sus capacidades productivas. Además, muchas tienen el objetivo de convertirse en herramientas para repensar el rol del dinero en la sociedad, por lo que las primeras preguntas que surgen en torno a la creación de estas monedas suelen ser: qué tipos de intercambio se quiere promover, entre quiénes, y para qué.

En nuestro caso nos detendremos en la moneda social conocida hasta 2018 como "El Boniato" -actualmente ETICS ${ }^{14}$, que pertenece a la red El Mercado Social de Madrid (MESM), una red de producción, distribución, y consumo de bienes y servicios, constituida y basada en la inter-cooperación entre entidades y consumidores que comparten los principios de la ESS (Carrero, 2018). El Boniato surge prácticamente a la par que esta red en torno a 2011. Sobre la utilidad de la moneda, la persona que coordina a día de hoy la comisión de moneda de esta red, en una entrevista mencionaba lo siguiente:

[El Mercado Social] habla de intercambios, producción y consumo, y aquello que une productores y consumidores es el método de intercambio, que es la moneda. [...] entonces cómo se quiere abarcar los dos ejes, y aquello que los une, por eso se decide lanzar moneda...!, la cual se entiende como "lo que cierra un poco el círculo de lo que es un mercado social ético".

Esta moneda tiene un carácter "complementario" y no "alternativo" respecto a la moneda oficial -el euro, en este caso-, lo que quiere decir que no aspira a ser una herramienta sustitutiva. Ambas monedas conviven en una relación de equivalencia 1:1 en la red, y permiten a las entidades adscritas a esta pagar con las dos monedas o con una mezcla de ambas, y cambiar de una a otra (aunque solo si se trata de una entidad y no de un consumidor). En este sentido, se ve como este tipo de iniciativas más bien conviven o se articulan con el modelo económico dominante, buscando complementarse con este, pero potenciando la realización de intercambios realizados bajo otra lógica (no acumulativa, ni especulativa). Como menciona la coordinadora de la comisión de moneda del MESM:

El Mercado Social, digamos, es una experiencia socialdemócrata, no es una experiencia anarquista, convive con el sistema. Entonces digamos que el modelo de moneda que tiene es similar. No es una moneda de crédito mutuo donde $[\ldots]$ el dinero como manera de intercambio desaparece [...], lo que promueve es una mayor circulación de los intercambios del mercado social.

A diferencia de otras experiencias de moneda social basadas en el sistema de crédito mutuo (como los sistemas LETS) ${ }^{15}$, el Boniato funciona como un sistema de bo-

14 Veasé: https://etics.mercadosocial.net/

15 Lo que llamamos LETS (Local Exchange Trading Systems), son redes locales de intercambio, sin ánimo de lucro, en la que los bienes y servicios se intercambian sin necesidad de usar la moneda de curso legal. En su lugar, utilizan un sistema de crédito mutuo en el que se permite a los usuarios no hacer intercambios directos y 
nificaciones que se aplica a los consumidores (similar a los programas de puntos que tienen algunas empresas para fidelizar clientes y aumentar ventas), creándose moneda al realizar intercambios dentro de la red. Por lo que con cada compra que se hace a un proveedor del MESM, el consumidor recibe una bonificación en forma de boniatos sobre una cuenta personal que se abre en el MESM para cada consumidor. Este descuento, a su vez, se le resta al proveedor, y si el proveedor no tiene boniatos ya acumulados en su cuenta sobre los que restar esta bonificación, esta se convierte en saldo negativo, o lo que es lo mismo, en deuda de la entidad hacia el MESM (existiendo unos límites de endeudamiento que aseguran la convertibilidad de la moneda) ${ }^{16}$.

El uso de esta moneda tiene como fin principal generar la adhesión de los miembros de la red que constituye el MESM, favorecer los intercambios dentro de esta esfera y promover los principios de la ESS como base para organizar las relaciones económicas. $\mathrm{Y}$ el hecho de permitir la convertibilidad entre ambas monedas, busca favorecer la incorporación paulatina de empresas de la economía formal a la dinámica del mercado social y de la ESS, asumiendo la idea de que si no se mantienen algunos vasos comunicantes, será muy difícil que nuevas empresas se incorporen a este circuito. De este modo, podemos decir que esta iniciativa genera una tensión entre dos lógicas, en tanto que, por un lado, rompe con la lógica del sistema monetario oficial -en cuanto que se crea dinero al margen de este $-{ }^{17}$, pero, por otro lado, mantiene una articulación clara con esta lógica al posibilitar su convertibilidad.

Ahora bien, en la práctica se ha visto que el intercambio en Boniatos ha ido decreciendo desde su creación a la vez que se ha ido cuestionado cada vez más su utilidad entre los miembros de la red. Lo cual motivó que desde la propia red se abriese un proceso de reflexión colectiva -entre finales de 2016 y principios de 2017-para saber si continuar o no con esta propuesta. Tras este proceso se tomó la decisión de continuar con la iniciativa, pero realizando algunos cambios que se definieron a partir de un estudio -denominado "El Reboniato"- que llevaron a cabo desde la red, sobre los usos que había tenido la moneda en la red. Las reflexiones recogidas en este estudio, y que utilizamos para llevar a cabo nuestro propio análisis, apuntaban a algunas limitaciones de esta experiencia.

En este sentido, uno de los principales factores que se apuntaba en este estudio como causante del escaso uso de este sistema de intercambio, era la escasa variedad de bienes y servicios dirigidos al consumidor final que se ofrecían en este, y su concentración en un espacio muy limitado, en un barrio concreto de la ciudad de Madrid. Esta cuestión se señalaba tanto a través de los verbatim recogidos de los miembros del MESM en este estudio, como en una entrevista que realizamos con la coordinadora de la comisión de moneda:

¿En cuántos sitios puedes gastar tus Boniatos? ¿todas las semanas la gente puede gastar sus Boniatos? Al final es super residual. No sé en otros barrios, pero fuera

estar en saldo negativo. Las transacciones se recogen en una localización central abierta a cualquier miembro y la suma de todas las cuentas participantes es siempre cero.

16 En este sentido, el MESM, funciona como "banco descentralizado", facilita la herramienta de pago, el registro de los intercambios y el control del saldo negativo acumulado. Con cada transacción recibe también un pequeño porcentaje de bonificación para mantener este funcionamiento logístico.

17 En los años que estuvo activo el boniato, se generaron intercambios equivalentes a unos $12.000 €$. 
de Lavapiés no hay nada. Cuando gastas una vez en no sé dónde y hasta dos meses después no lo gastas... se te olvida". (Miembro del MESM, en el estudio del Reboniato).

Una moneda al final va muy orientada al consumidor final, y el mercado social ahora mismo no sé cómo está [...]. En su momento era un 67\% servicios, entonces mucha consultoría tienes que necesitar [...]. Para mí lo ideal sería conseguir un mercado diverso que consiga ofrecer un estilo de vida dentro del mercado social con tu propia moneda. O sea, hay cooperativas de ópticos, hay cooperativas de ginecólogas, hay cooperativas de salud integral, hay mercados... hay sitios donde tenemos que ir a decir ‘¿quieres pertenecer al Mercado social?’ y salir de Lavapiés de una vez por todas. (Coordinadora de la comisión de moneda del MESM)

Otro factor que se asocia a la escasa circulación de esta moneda en el estudio, es la "falta de compromiso" con el uso de la moneda dentro de la propia comunidad del MESM. Gran parte de este problema venía dado por el hecho de que varios establecimientos no aceptaban el pago del 100\% en Boniatos, o directamente no los aceptaban, lo que desincentivaba su uso entre los consumidores. Según detallaba el estudio, esto parecía responder tanto a la complejidad del funcionamiento de las bonificaciones y del registro de los intercambios ${ }^{18}$, como al miedo a la "deuda" que se genera en las entidades al realizar las bonificaciones. Y de esta cuestión se concluía que había en verdad un desconocimiento de la posibilidad de convertibilidad de la moneda, así como de los productos y servicios que podían intercambiar para equilibrar su saldo negativo o gastar los Boniatos acumulados.

Lo identificas con un marrón. Es un proceso complicado de gestionar, tanto para nosotros que estamos cobrando, como para las personas que van a pagar. Las personas no tenían claro cómo era el proceso y era complejo por eso; cuando alguien te dice que quiere bonificarse, entramos en pánico; tiene que ser un proceso sencillo, igual de fácil mínimo que pagar con euros, tanto para el comerciante como a la consumidora. (Miembros del MESM, en el estudio del Reboniato)

No obstante, resulta interesante remarcar también que el sistema de bonificaciones del Boniato (el mecanismo de "descuentos" que aplica), no parece que haya sido -hasta ahora al menos- lo que más ha motivado su uso, sino más bien su factor ideológico, de apoyo a la causa social y medioambiental considerada "justa" que se promulga a través del discurso de la ESS y se busca promover con su uso. En este sentido, este caso nos remite a la dimensión moral a la que se apela en este tipo de prácticas de ESS, y que, en última instancia, las dota de sentido.

Por otra parte, a las limitaciones ya señaladas en el estudio del Reboniato, hay que añadir el hecho de que la oferta de productos y servicios que se pagan en Boniatos solo

18 El Boniato solo ha funcionado de manera virtual, exceptuando la impresión puntual de billetes para las ferias organizadas en el marco del mismo mercado (siendo la moneda impresa solo válida durante los días de feria). En el día a día, hasta 2016 se operaba a través de una interfaz web en la que cada socio/a del mercado disponía de una cuenta propia de Boniatos, y cada vez que hacía una compra, a posteriori, a través de la web debía notificarlo y solicitar la bonificación que le correspondía a la tienda donde había comprado. 
pueden provenir de entidades que operan en la "economía formal" (es decir, de entidades con entidad jurídica y estén censadas en la Agencia Tributaria). Este hecho es una diferencia de funcionamiento notable respecto a muchas de las monedas sociales basadas en el crédito mutuo, donde abunda la oferta de servicios prestados por particulares y no se crea una línea divisoria tan marcada -y ciertamente excluyente- entre economía formal e informal. En este sentido, y como apunta la coordinadora de la comisión de moneda del MESM, hay que tener en cuenta que "cada moneda se busca su propósito [...] tienen detrás una ideología, un instrumento y una comunidad que decide"19. Y, en este caso, se entiende que la apuesta por generar una "alternativa económica", se circunscribe exclusivamente al ámbito de la economía formal, dejando fuera de esta lógica a iniciativas que por diferentes motivos no operan dentro de este ámbito ${ }^{20}$.

Con todo ello, el análisis realizado sobre esta experiencia nos muestra algunos límites y resistencias existentes para crear una esfera de intercambio asociada a los valores de la ESS, en el marco de la economía formal. Pero también nos permite ver cómo la idea de "transformación" y "emancipación" que sostienen estas iniciativas pueden servir a significados muy dispares, ya sean estos definidos por las decisiones de sus miembros, o por la determinación de los contextos donde surgen. Ahora bien, lo más interesante de esta reflexión, es que nos permite ver cómo se da una articulación -ya sea voluntaria u obligada- entre distintas lógicas económicas. De esta forma, con este caso se han tratado de mostrar algunos elementos que evidencian el escenario de pluralidad económica que tanto construyen como reafirman este tipo de iniciativas definidas como ESS.

\subsection{Fiare Banca Ética}

El último caso en el que queremos detenernos es el de la entidad Fiare Banca Ética, una cooperativa dedicada a las finanzas éticas y solidarias. Fiare nace en 2003 en el País Vasco, a partir de diversos grupos interesados en las finanzas éticas que se unieron con la intención de generar una herramienta financiera basada en principios éticos de la ESS. La entidad fue creada con la misión específica de captar ahorro para financiar y fomentar proyectos que pudiesen tener un impacto positivo -a nivel social, ambiental y económico- de acuerdo a estos principios. Así, tal como señala el responsable de relaciones asociativas de la entidad: "nos vemos a nosotros mismos un poco como el motor financiero de la economía social y solidaria. Nuestra misión es la captación de ahorro y financiar proyectos con vocación de transformación social".

Siguiendo esta propuesta, en 2005, mientras se comienza una campaña de recogida de capital que les permitiese obtener una licencia bancaria propia ${ }^{21}$, se firma un contrato con la entidad italiana con fines similares, la Banca Popolare Ética, con el fin de comercializar algunos de sus productos financieros en España y obtener

19 En este caso, se observa que hay apuesta por generar una "alternativa económica" dentro de los marcos de la economía formal, y por ello no se aceptarían intercambios informales, por entender que esto supondría entrar unas dinámicas de competencia respecto a quienes pagan impuestos. Se ve así, por ejemplo, el rechazo a la propuesta que se hizo desde el MESM de hacer tarjetas de crédito que funcionaran con Boniatos.

20 En el caso del Boniato no se aceptan intercambios informales por entender que esto supone entrar en una dinámica de competencia respecto a quienes pagan impuestos.

21 Según la normativa del Banco de España era necesario contar con un capital de 6 millones de euros para poder operar con licencia propia lo que dificultaba su puesta en marcha en el corto plazo. 
nuevos clientes. Y tras un proceso de trabajo conjunto de varios años, en 2014, entre las dos instituciones, se decide la integración de ambas en una sola cooperativa de ahorro y crédito configurándose Fiare Banca Ética. Ese mismo año, la entidad obtiene finalmente la licencia para actuar bajo la supervisión del Banco de España, a la vez que abre su primera sucursal en Bilbao ${ }^{22}$. Así, ya para finales de 2018 la entidad sumaba cerca de 2.800 personas socias y más de 3 millones de capital social en España, mientras que Fiare Banca Ética en su totalidad tenía más de 42.162 socios y 67 millones de capital social.

Prestando atención a cómo Fiare Banca Ética trata de plasmar su adhesión a los valores de la ESS en el plano práctico encontramos varias cuestiones reseñables. La entidad tiene establecida una política retributiva que fija que la diferencia salarial entre el mayor y el menor sueldo no puede ser más de 6 veces el menor, siendo la diferencia entre la retribución máxima y la mínima en 2017 de 4,92 veces. Se ajusta así una horquilla salarial, que es sin duda muy inferior a la que aplican otras entidades del mismo sector financiero. Luego, además, cuenta con planes de formación, igualdad y conciliación familiar para sus trabajadores, y, en el plano de los proveedores, trata de priorizar a entidades que se identifiquen con los valores de la ESS.

Por otro lado, la cooperativa tiene un fuerte compromiso con la transparencia ${ }^{23}$, así como presume de tener como pilar fundamental en su funcionamiento el principio de participación y democracia. Este hecho se concreta en su forma jurídica como cooperativa, y en la adopción de una compleja estructura organizativa y de gobernanza que trata de proveer y asentar espacios de participación en todos los niveles organizativos. Dentro de esta estructura organizativa destacan los "Grupos de Implantación Territorial" (GIT), espacios que, entre otras funciones, tienen como misión la realización de una evaluación ético-social de los proyectos que solicitan crédito en los lugares donde el banco tiene implantación.

Ahora bien, más allá de los principios que guían a esta entidad y la forma en que se llevan al plano práctico, queremos detenernos en algunas situaciones y debates que nos empujan de nuevo a hablar de formas de articulación entre distintas lógicas y modos de sociabilidad económicos, y que, a su vez, ilustran el debate sobre los límites y potencialidades existentes para la construcción de una entidad financiera regida bajo otros parámetros distintos a los de la banca convencional.

La primera cuestión relacionada con este debate tiene que ver con el hecho de que opera en un sector supuestamente antagónico a los valores de la ESS -como es el sector financiero-, así como con las complejas exigencias que el Banco de España impone para operar en este sector (por ejemplo, en relación a la capitalización necesaria que se exige para poder operar). También, se encuentra con encuentra con límites sobre todo en relación a la gama de servicios que puede ofrecer, en comparación con otras entidades del sector -en cuanto a oferta y condiciones-, lo que hace que la implantación de servicios bancarios dirigidos a particulares no

22 En 2018 Fiare contaba ya con 296 trabajadores, cerca de 2800 personas socias y más de 3 millones de capital social en España, mientras que a nivel general tenía más de 42162 socios y 67 millones de capital social. También en este momento ultimaba los preparativos para la apertura de una nueva sede en Madrid.

23 Especialmente en lo que se refiere a mostrar públicamente información sobre el tipo de proyectos que financia y sobre los compromisos públicos que tiene adquiridos, como puede observarse en la información recogida en el Balance Social que elabora anualmente. Véase: https://balancesocial.fiarebancaetica.coop/ 
haya sido fácil, y hayan tenido que hacer grandes esfuerzos para poder "ser competitivos" en su sector.

Aunque en este sentido se han producido notables progresos en los tres últimos años, como la introducción de las tarjetas de débito o crédito, o la posibilidad de domiciliación de nóminas y de realizar transferencias bancarias, siguen existiendo limitaciones respecto a los servicios que pueden prestar. Por citar dos ejemplos: por un lado, los depósitos que ofrece la entidad tienen una rentabilidad notoriamente más baja que la de las entidades convencionales, y, por otro lado, no es posible sacar dinero gratis de un cajero, para lo que disponen únicamente de un acuerdo con dos cooperativas de ahorro y crédito (Grupo Caja Rural y Laboral Kutxa, que permiten la retirada de dinero en efectivo aplicando una comisión pactada de $0,80 €$ ). Todo ello hace que sea fundamental para la entidad el establecimiento de acuerdos con otras entidades que son percibidas como "próximas" (fundamentalmente cooperativas de ahorro y crédito), aunque no concuerden con todos sus valores, con el fin de tener una cartera de servicios mas o menos análoga a la de otras entidades del sector. Como mencionaba el responsable de relaciones asociativas: “...nos relacionamos con otros del sector porque si no, no podríamos hacer lo que hacemos".

Por otra parte, otro de los límites con el que se encuentra esta entidad para trabajar de acuerdo a los principios de la ESS, tiene que ver con la existencia de un exceso de pasivo y una insuficiente generación de proyectos en el marco de la ESS que permitan canalizar ese ahorro. Este hecho plantea en la entidad -aun sin quererlo- la necesidad de alzar la mirada hacia otros sectores para dar crédito a iniciativas que se encuentran al margen de lo que llamamos "prácticas de ESS", aunque sí compartan -consciente o inconscientemente- algunos principios con ella. Esto genera en cierto modo una situación de tensión interna en relación al objetivo de la entidad de fomentar un circuito económico alternativo basado en estos principios, y de hecho es visto desde la entidad como un límite de la propia ESS:

Hemos hecho una reflexión porque tenemos todo el tema de que tenemos mucho ahorro y nos cuesta canalizarlo como crédito y decimos, bueno, tenemos que canalizarlo a otras vías: economía del bien común... Entonces a lo mejor tenemos que alzar la mirada de la ESS y mirar a otros ámbitos. Y eso es una crítica a la ESS, tampoco la Economía Social y Solidaria nos da proyectos suficientes como para canalizar nuestro ahorro y nos gustaría tener una filiación mayor de algunas redes de Economía social y solidaria. (Responsable de relaciones asociativas de Fiare).

Sin embargo, el tema que mejor ilustra el planteamiento que queremos formular con este artículo sobre la articulación de lógicas y modos de sociabilidad económicos que se da en este tipo de iniciativas, lo encontramos en los debates surgidos en la entidad a raíz del anuncio de comercialización en España de un Fondo de Inversión Responsable gestionado a través de Ética SGR, una sociedad controlada por Fiare Banca Ética ${ }^{24}$. Ética SGR es vista, en palabras del director general de Banca Ética,

24 Los fondos de inversión socialmente responsable (ISR) son instituciones de inversión colectiva que eligen los activos que conforman su cartera en función de criterios ambientales, sociales y de gobierno corporativo (ASG) introduciendo, a la búsqueda de la rentabilidad, criterios de tipo ético. Cabe señalar que la creación de Ética SGR es destacada en Italia por Banca Ética (según indican en su página web) como uno de los hitos más importantes que han conseguido en la historia del banco por su carácter pioneros e innovador en el sector. 
como un instrumento que permite adaptar "a los mercados bursátiles el principio en que se basan las finanzas éticas; a saber: lograr que los ahorradores sean plenamente conscientes de cómo se usa su dinero" "25. Al fusionarse Banca Ética con Fiare, se decide comenzar a comercializar estos Fondos de Inversión Responsables también en España, asumiendo la realidad que ya existía en Italia donde la comercialización de estos fondos se da desde 2002 con notable éxito (ya para 2017 habían captado a través de ellos 573 millones de euros).

La selección de los valores en los que se puede invertir los fondos que gestiona Ética SGR, se realiza a través de un largo proceso de selección entre las empresas que cotizan en bolsa o de la deuda de diferentes Estados, y en palabras del fondo, se busca con ellos "respetar el medio ambiente y los derechos humanos, invertir en la economía real y premiar a empresas y Estados que adoptan prácticas virtuosas. Todo ello sin renunciar a las oportunidades de rentabilidad, con una óptica de medio-largo plazo $^{26}$ ". Este proceso se define, pues, en base a criterios ambientales y sociales en el que se van descartando progresivamente empresas y sectores por el tipo de actividad que desempeñan o por sus prácticas laborales, sociales y/o medioambientales ${ }^{27}$.

En la preparación de la puesta en marcha de este instrumento financiero en España se realizaron varias sesiones informativas dentro de los GIT para explicar cómo funciona Ética SGR y el producto que se iba a comercializar, y a partir de estas sesiones surgieron algunos debates interesantes entre los socios de la entidad. A partir de estas sesiones se elaboró un documento con una síntesis de los puntos negativos y positivos identificados en estos debates, en el que se reconocía la existencia de la pluralidad de posiciones había hacia esta cuestión entre la base social del proyecto. En este documento - que fue cedido para el presente análisis- se recogía incluso que la puesta en marcha de la comercialización de estos productos había producido algunas bajas de socios en la entidad.

Entre los puntos favorables para la comercialización de estos fondos se destacaban el trabajo en red con organizaciones con mayor capacidad de impacto; la posibilidad de llegar a un público más amplio; la apuesta por la no-realización de operaciones a corto plazo, sino medio o largo plazo; la contribución que dicho fondo aportaba a la sostenibilidad del grupo Banca Ética; así como la posibilidad y voluntad de llevar a los mercados financieros los principios de las finanzas éticas, para así poder incidir en los comportamientos de las empresas y el accionariado activo.

25 Declaraciones extraídas de la noticia "Banca ética se hace con el 51\% del capital de Ética SGR". Disponible en: https://www.eticasgr.it/es/blog/banca-etica-sale-al-51-del-capitale-di-etica-sgr/

26 Forma en la que explica Ética SGR el funcionamiento de sus fondos. Extraído de: https://www.eticasgr.com/es/ inversion-responsable

27 En este proceso de evaluación compuesto de numerosos indicadores, se descartan de partida a los sectores financiero, petrolífero y extractivo, empresas que tengan comportamientos contrarios o hayan violado alguna normativa internacional (como aquellas que no respetan las convenciones sobre la prohibición de minas antipersonas o sobre la fabricación de bombas de racimo, entre otras), o están relacionadas con armas, tabaco o el juego. Y se evalúan otros numerosos indicadores. En cuanto a la deuda pública de países, se descarta a aquellos que contemplan la pena de muerte o no respetan libertades políticas o derechos civiles. De la misma forma, Ética SGR, no realiza operaciones a corto plazo, ni usa instrumentos derivados complejos con fines especulativos. De este proceso se seleccionan unos 150 valores invertibles, entre los cuales se realiza una evaluación económica para establecer la selección final en base a lo que Ética SGR define como "las experiencias más virtuosas con base al análisis de los aspectos sociales, medioambientales y de gobierno de los emisores" (Citado en "La inversión responsable de Ética SGR. Disponible en: https://www.eticasgr.it/es/il-nostro-investimento-responsabile/ investimenti-responsabili-di-etica-sgr/). Por otro lado, todo este proceso se complementa con un trabajo activo de incidencia entre las empresas seleccionadas para intentar mejorar sus comportamientos. 
Por su parte, entre los puntos negativos se destacaba: las dudas sobre la capacidad de transformación real de estos fondos; el desacuerdo que podía darse sobre el hecho de invertir en determinadas empresas y el miedo a la reputación que pudiese generar esto en el banco; o simplemente la contradicción que podía suponer para la entidad la inversión en mercados financieros en el que participan tipologías de empresas muy distintas respecto a la actividad y discurso histórico construido en torno a la ESS y en la inversión en la "economía real".

Además, entre las opiniones negativas a la comercialización se llamaba la atención sobre cómo al apostar por esta iniciativa se estaba dando más prioridad a la comercialización de un producto que no era demandado por la masa social más cercana a los GIT, clientes y socios, frente a otros productos - como los préstamos- que sí lo eran. También, se acusaba a la entidad de primar el interés comercial frente a la búsqueda de una mayor coherencia con los principios de la ESS, manifestando que entendían que era incompatible la promoción de las "finanzas éticas" como movimiento que apoya la economía real, con la comercialización de un instrumento -como un fondo de inversión- que favorece la financiarización de la economía.

En cambio, aun reconociendo los riesgos que había en esa apuesta, entre las opiniones favorables se destacaban las posibilidades que ofrecía el producto para llegar a gente alejada de las finanzas éticas y de la ESS. En esta línea, el responsable de relaciones asociativas entrevistado indicaba cómo el fondo podía ser una herramienta estratégica para incidir en el ámbito de los mercados financieros.

Nos metemos en fondos de inversión por una cuestión ideológica. Aunque parezca contradictorio desde Banca Ética pensamos que tenemos que entrar en los mercados financieros para llevar los principios de banca ética a un mundo hostil, para contaminar los mercados financieros. Tenemos que ensuciarnos las manos para influir en ámbitos y en mercados donde estos principios no llegan y donde si no estuviésemos sería mucho peor de lo que es en realidad.

Con ello, creemos que el debate sobre los fondos de inversión es un excelente ejemplo de la tensión que planteamos aquí en torno a la articulación entre diferentes lógicas y modos de sociabilidad económicos, y que en este caso se expresa en el dilema entre la búsqueda de una mayor coherencia con la forma en que se adhiere la entidad a los principios de la ESS, y el anhelo de llegar a gente más alejada de las finanzas éticas. El trabajador de Fiare citado anteriormente manifestaba de esta forma esta tensión:

Tener fondos de inversión éticos tiene un punto de campo de minas, yo lo reconozco, sin ninguna duda. Pero tiene algo interesante y es que se llega a mucho más público del que llegamos. Tipo, yo voy con los depósitos de Fiare y no llega mucho. Si vas con una herramienta tipo fondo de inversión ético puedes atraer a muchísima gente que de otra manera ni olerían lo que son las finanzas éticas. Y ese es otro argumento que también es interesante y hay que poner encima de la mesa.

Y es esta misma tensión, la que consideramos que está latente en la diversidad de situaciones que existen entre la base social de esta misma entidad, en relación a la diversidad de intereses que hay respecto a esta cuestión de los fondos de inversión, como expresaba el responsable de relaciones institucionales: 
Hay muchas entidades que nos piden esto que están en Fiare. // ¿Qué entidades? ¿El socio militante de REAS [Red de Economía Alternativa y Solidaria]? // No. Pero la organización religiosa de monjas que tiene fondos, esta sí y otras grandes organizaciones también utilizarían esta herramienta si la tuvieran. Entonces, aunque parezca sorprendente, y en la base social no se lo creían, hay gente que contrataría esta herramienta si la tuvieran. Algunas gestionan mucha tesorería y de meter un depósito a plazo a un fondo, pues es importante para su tesorería. Entonces, tenemos una parte de nuestra base social que nos pide esta herramienta como la pidieron en Italia.

En conclusión, el caso de Fiare nos ilustra sobre algunos dilemas en torno al debate que aquí presentamos -respecto a la articulación de lógicas y modos de sociabilidad económicos que se pueden dar en iniciativas identificadas como ESS-, pero con el especial interés aquí de que se plantean en uno de los sectores de actividad -el financiero- donde, a priori, puede resultar más difícil construir una alternativa inspirada en los principios de la ESS, por cuestiones como la escala de actuación o las exigencias técnicas que se dan para operar en este sector. Por otro lado, este caso nos presenta algunos debates sumamente interesantes para la discusión propuesta, como las cuestiones relativas al tipo de alianzas que se ve obligada a hacer esta entidad para operar en su sector, o los debates que se han planteado entre su base social, sobre cuáles deben ser las líneas de actuación prioritaria de la entidad o cómo puede y/ o debe desarrollarse su acción en el marco de los que consideran los principios de la ESS.

\section{A modo de conclusión:}

A la luz de las cuatro experiencias presentadas en las páginas anteriores hemos podido ver algunos ejemplos de cómo el cuerpo teórico de principios ético-políticos que compone el paradigma de la ESS, se plasma en una diversidad de situaciones y prácticas económicas concretas. Nuestro interés estaba aquí puesto especialmente en rescatar esta diversidad, en conocer cómo estas iniciativas se desarrollan, se insertan y se relacionan con su contexto concreto, y cómo este - a su vez- las puede impulsar o limitar. Todo ello partiendo de la premisa de que la mayor parte de los estudios que giran en torno a la ESS, desatienden esta dimensión práctica, cotidiana y contextual.

Teniendo en cuenta esta cuestión, y a la luz de los casos presentados, creemos que la perspectiva etnográfica, a partir de la que hemos construido los casos presentados aquí, es de gran utilidad para ver cómo la propuesta abstracta de la ESS toma cuerpo de diversas formas, en función de su particular composición y organización interna, del contexto -social, histórico, territorial y político- en el que se inscriben estas iniciativas, y del tipo de actividad que desarrollan. Vemos así cómo esta aproximación nos permite mostrar algunos ejemplos de los dilemas que se afrontan y se plantean en el día a día de estas iniciativas - de forma más o menos consciente-, y nos permite analizar la constante articulación que se da en estas experiencias entre diversas lógicas y modos de sociabilidad económicos, que a veces incluso se contraponen de forma paradójica.

Siguiendo esta idea, en el texto hemos presentado algunas situaciones y debates que creemos que muestran dicha articulación: en el caso de la cooperativa Agresta, 
en torno a su preocupación sobre cómo afrontar el crecimiento sin afectar a la forma de gobernanza cooperativa; en el caso de la asociación El Rincón Lento, en torno a la búsqueda constante de un equilibrio entre el fin social perseguido por el proyecto y la actividad comercial que garantice su sostenibilidad económica; en el caso de la moneda social el Boniato, en torno a las dificultades que supone crear una esfera de intercambio autónoma que funcione bajo los criterios de la ESS dentro de los márgenes de la economía formal; o en el caso de la Banca Ética Fiare, en torno a la propuesta de comercialización de determinados productos que les permitirían promover la ESS entre sectores más alejados a la base social más "pura", a riesgo de que esto suponga perder coherencia respecto a los principios de la ESS. Además, de forma general, vemos que en estos casos se hacen patentes los constantes equilibrios que son realizados para gestionar la pluralidad de sus miembros o de su base social, así como la variabilidad que se da en torno a la definición de lo que significa "ser o hacer ESS".

Así, incidir en este tipo de aproximación para el estudio de la ESS centrada en el análisis de algunas de las tensiones identificadas, tiene la intención de evitar que caigamos en esquemas binarios que -a nuestro juicio- simplifican excesivamente esta realidad (esto es, por ejemplo, lógica capitalista vs. no capitalista; modo de sociabilidad competitivo vs. cooperativo; o presentar sin apenas problematizar las iniciativas de ESS como experiencias "positivas" que actúan en un contexto "negativo", entre otros). Lo que nos llevaría a entender las iniciativas de ESS como una simple proyección de tipos ideales con poco valor analítico. En consonancia con este planteamiento, Reygadas expresaba que

Lo que encontramos en las investigaciones empíricas no es un modelo único de economía alternativa, presente en todos los casos y en todas las experiencias, sino una gama muy diversa de búsquedas. [...] Dicho de otra manera, hay que ir más allá de la mera evaluación normativa y clasificatoria que divide las experiencias en dos grupos, las positivas y las negativas, las puras y las impuras, las que coinciden con nuestra visión del mundo y las que difieren. Solo así se podrá avanzar hacia una perspectiva analítica que busque la compresión de los procesos emergentes, ninguno de los cuales es blanco o negro, sino que se trata de fenómenos complejos en los que intervienen diversos actores y que se encuentran atravesados por contradicciones, paradojas e impedimentos estructurales $(2014: 17,21)$.

Por otro lado, y en relación con esta última idea, queremos destacar cómo es necesario tener presente que todas estas iniciativas se insertan en un contexto dominado por una lógica basada en la acumulación capitalista. Y, en este sentido, es la perspectiva etnográfica adoptada la que nos permite observar precisamente cómo el margen de actuación y potencial transformador y emancipatorio de estas experiencias respecto a la dinámica de mercado en el que operan, es limitado en términos estructurales. Así mismo, esta mirada nos permite advertir cómo la lógica de acción de estas iniciativas no responde a una sola lógica sino a varias, lo que nos lleva a plantear la imposibilidad de identificar una lógica o un modo de sociabilidad único y coherente dentro de este tipo de iniciativas de ESS, sino más bien una articulación de varios de estos.

Por último, la aproximación etnográfica también nos ha permitido ver cómo la racionalidad de este tipo de estas experiencias no se puede entender $-\mathrm{o}$ al menos no 
únicamente- desde los principios maximizadores y utilitaristas de la lógica capitalista pues, en última instancia, no es la búsqueda de la ganancia económica la que dota de sentido su actuación sino, más bien, el sentido y el significado que los miembros o la base social otorgan a esta forma de organizarse y de desarrollar una actividad económica. Esta cuestión nos lleva a destacar la importancia de la remisión constante y explícita que se hace en estas experiencias a una suerte de "moralidad", en tanto que, por un lado, esta decidida orientación ético-moral sirve de sostén y legitimación de sus prácticas, $\mathrm{y}$, por otro, hace especialmente visible en ellas la incrustación de lo económico en lo social que se da en estas prácticas.

Consideramos que estas reflexiones son importantes, desde un punto de vista analítico, principalmente por dos cuestiones. En primer lugar, porque usualmente se apela a estas iniciativas, o según ellas mismas se presentan, como "economías transformadoras", "economías alternativas" u "otras economías" de forma muy vaga y poco problematizada. Pero, también, porque muchos de los análisis apoyados en la teoría neoclásica, más reduccionistas, no suelen prestar atención a cómo este tipo de experiencias revelan una diversidad de lógicas y formas diferentes de "pensar y hacer economía", y en última instancia, de "producir y reproducir la vida" (Lucas y da Silva, 2014). En este sentido, como señala Hillenkamp, el análisis de las experiencias de la ESS,

“constituye una herramienta imprescindible para los que rechazan el carácter supuestamente ineluctable del modo de producción capitalista y buscan visibilizar y promover otras relaciones de producción y de intercambio y otras relaciones sociales" (Hillenkamp, 2012:233).

Con todo ello, planteamos que estas experiencias de ESS no dan pie -como sí han planteado algunos autores- a la concreción de un "escenario postcapitalista" (Gibsom-Graham, 2011), sino más bien a la concreción de un "escenario de pluralidad económica", tal como lo describen autores como Laville (2009a) o Hillenkamp (2012). Y este escenario de pluralidad económica, más que representar la coexistencia entre diferentes "formas de economía" más o menos delimitadas, se debería caracterizar más bien por ser una suerte de juego de equilibrios cotidianos entre los diferentes principios económicos - tal como lo definía Polanyi (1976)-, así como por la existencia de una tensión y articulación constante entre lógicas y modos de sociabilidad incluso contrapuestas.

Finalmente, desde un plano metodológico, con este articulo queríamos enfatizar la necesidad de seguir profundizando en el análisis de las iniciativas que se autodenominan "de ESS", a partir de la realización de estudios de caso como proponíamos aquí, pues vemos que esta puede ser una forma muy útil de problematizar el pensamiento económico reduccionista dominante, y ampliar nuestra comprensión de los procesos económicos.

\section{Referencias bibliográficas}

Alquezar, Raquel; Homs, Patricia; Morello, Nuria et al. (2014). "Prácticas cooperativas: ¿estrategias de supervivencia, movimientos alternativos o reincrustación capitalista?". Ars \& Humanitas, 8: 151-165. 
Blanc, Jerome (2011). "Classifying 'CCs': Community, Complementary and Local Currencies”. International Journal of Community Currency Research, 15: 4-10.

Caille, Alain (2009). "Sobre el concepto de economía en general y el concepto de economía en particular”, en, A. Caillé, C. Ferraton, J.L. Laville, J. L. Coraggio (org) ¿Qué es lo económico? Materiales para un debate necesario contra el fatalismo. Buenos Aires: CICUS.

Calle, Ángel y Casadevante, José Luis (2015). “Economías sociales y economías para los bienes comunes". Otra Economía, 9: 44-68.

Carrero, Gaël (2018). "Mercados sociales: un instrumento para la generación de tejido productivo en el marco de un proyecto transformador de la economía". Dossiers Economistas Sin Fronteras, 31:51-62.

Comas, Dolors (1998). Antropología económica. España: Ariel.

Coraggio, José Luis (2012). "La Economía Social y Solidaria (ESS) en América latina", en A. Guillén; M. Phélan, Construyendo el Buen Vivir. Universidad de Cuenca/PYDLOS, Cuenca, 236-256.

Coraggio, José Luis (2014). "Una lectura de Polanyi desde la economía social y solidaria en América Latina". Cadernos Metropole. 16(31): 17-35

Corrons, August (2015). "Monedas complementarias en pro de la sostenibilidad y el desarrollo: enfoque panárquico". Trabajo de Final de Máster. Institut Interuniversitari de Desenvolupament Local. Universitat Jaume I - Universitat de València

Darbus, Fanny (2015). "Loin de la subversion et de la transformation sociale: les pratiques de l'économie sociale et solidaire". Agora débats/jeunesses, 69:7-22. DOI 10.3917/ agora.069.0007

De Sousa Santos, Boaventura; Rodriguez, Cesar. (2011). "Introducción. Para ampliar el canon de la producción", en B. Sousa Santos (coord.) Producir para vivir. Los caminos de la producción no capitalista. México: Fondo de cultura económica, 15-62.

Fassin, Didier; Eideliman, Jean-Sébastien (dir.) (2012) Économies morales contemporaines. Paris: La Découverte.

Fassin, Didier (2018). Por una repolitización del mundo las vidas descartables como desafio del siglo XXI. Buenos aires: Siglo XXI.

Fernandez, Anna; Miró, Ivan. (2016). La economía social y solidaria en Barcelona. Barcelona: Marge Books.

Gibson-Graham. J. K. (2011). Una política poscapitalista. Bogota: Siglo del Hombre Editores.

Godelier, Maurice (1991). "L'objet et les enjeux", en Transitions et subordinations au capitalisme. Paris: Éditions de la Maison des sciences de l'homme, 7-56. DOI: 10.4000/ books.editionsmsh.6232.

Hespanha, Pedro (2009). "Da expansao dos mercados à metamorfose das economías populares". Revista Crítica de Ciências Sociais, 84: 49-63.

Hespanha, Pedro; Santos, Luciane, Da Silva, Beatriz; et al. (2015) "Mapeando as iniciativas de economia solidária em Portugal: algumas considerações teóricas e práticas”, en B. de Sousa Santos, y T. Cunha (eds.), Actas Coloquio Internacional Epistemologias do Sul: Aprendizagens globais sul-sul, sul-norte e norte-sul. Centro de Estudos Sociais, 465-475.

Hillenkamp, Isabelle (2012). "Economía solidaria y transformación social: pluralidad y tensiones, lecciones de Bolivia", en B. Marañon-Pimentel (ed.) Solidaridad económica y potenciales de transformación en América Latina. Buenos Aires: Consejo Latinoamericano de Ciencias Sociales (Coimbra), 231-258. 
Laville, Jean-Louis (Ed.) (2000). L'economie solidaire. Une perspective internationale, Paris: Desclée de Brouwer.

Laville, Jean-Louis (2004). "El marco conceptual de la economía solidaria", en J. L. Laville (ed.), Economía social y solidaria. Una visión europea. Buenos Aires: Altamira, 207-235.

Laville, Jean-Louis (2009a). “A economía solidária: Um movimiento internacional”. Revista Crítica de Ciências Sociais, 84:7-47.

Laville, Jean-Luis (2009b). "Definiciones e instituciones de la economía. Con Mauss y Polanyi hacia una Teoria de la Economia Plural”, en A. Caillé; C. Ferraton; J.L. Laville; J.L. Coraggio (org) ¿Qué es lo económico? Materiales para un debate necesario contra el fatalismo. Buenos Aires: CICUS. 1-41

Lucas dos Santos, Luciane y Da Silva, Beatriz Caitana (2014). "Mercado de trocas e moedas sociais em Portugal continental: os desafíos de uma cultura de emancipaçao social". Otra Economía, 8(15): 210-219.

Marques, Amaral (2011). La 'otra economía' en movimiento: Un estudio sociológico del movimiento social de la Economía Solidaria en Brasil. Tesis doctoral. Facultad de ciencias políticas. Universidad de Granada.

Meillassoux, Claude (1977). Mujeres, graneros y capitales: economía doméstica y capitalismo. México D.F-Madrid: Siglo XXI.

Narotzky, Susana (2010). "La economía social: conceptos teóricos y economía real. Una perspectiva antropológica”. Actas Congreso Internacional de Economía Social: the politics of social economies and labour control new perspectives on theory and practice. Escuela de Organización Industrial (Sevilla). [Online] Recuperado el 8 de marzo 2018 en: https://es.slideshare.net/slides_eoi/susana-narotzky-la-economa-social-conceptostericos-y-economa-real

Narotzky, Susana (2013). Economías cotidianas, economías sociales, economías sostenibles. Barcelona: Icaria.

Osorio, Daniela (2019). "Economía solidaria y feminismo(s): pistas para un diálogo necesario", en E. Santamaría; L. Yufra; J. De la Haba (eds.), Investigando Economías Solidarias (Acercamiento teórico-metodológicos). Barcelona: Asociación ERAPI / Laboratori Cooperatiu de Socioantropologia-Grupo de trabajo en Socioantropología de los mundos contemporáneos del Institut Català d'Antropologia, 97-106.

Pérez de Mendiguren, Juan Carlos; Etxezarreta, Enekoitz; Guridi, Luis. (2009). "Empresa Social y Economía Solidaria: diferentes conceptos para un mismo debate". Papeles de Economía Solidaria, 1:1-41.

Pérez de Mendiguren, Juan Carlos; Etxezarreta, Enekoitz (2015). "Sobre el concepto de economía social y solidaria: aproximaciones desde Europa y América Latina”. Revista de Economía Mundial, 40:123-143.

Poirier, Yvon (2014). "Economía social solidaria y sus conceptos cercanos. Orígenes y definiciones: una perspectiva internacional". [Online] Recuperado el 8 de marzo 2018 en: http://base.socioeco.org/docs/economie_solidaria_y_sus_conceptos_cercanos-poirierjulio-2015.pdf

Polanyi (1976). "El sistema económico como proceso institucionalizado", en M. Godelier, (comp.) Antropología y economía. Barcelona: Anagrama, 155-178.

Polanyi, Karl (1983). La grande transformation, Paris: Gallimard.

Rebón, Julián; Kasparian, Denise; Hernández, Candela (2015). "La economía moral del trabajo. La legitimidad social de las empresas recuperadas". Trabajo y Sociedad, 25:173-194.

Reygadas, Luis (2011) “¿Capitalismo 2?0? Etnografía de una empresa del mundo digital”. Maguaré, 25(1):165-202. 
Reygadas, Luis (2014) “Más acá y más allá de la utopía. Dilemas y potencialidades de las economías alternativas”, en L. Reygadas, M. Pozzio, M. A. Gracia, et al. (eds.) Economías alternativas: utopías, desencantos y procesos emergentes. México: UNAM-Iztapalapa, 11-48.

Reygadas, Luis; Pozzio, María; Medina, Alejandra (2015). "Cooperativas realmente existentes: cuatro décadas de trabajo y reciprocidad en un barrio popular de la Ciudad de México". Otra Economía, 9(17):110-122.

Sabin, Fernando (2016). "La economía solidaria, el movimiento cooperativista y los comunes". Economistas sin Fronteras. Madrid, 16:37-41.

Vaillancourt, Yves (2010). "El 'mapeo' de la economía social y solidaria: algunos retos". Otra Economía, 4(7):178-185.

Verschuur, Christine; Guérin, Isabelle; Hillenkamp, Isabelle (2015) Une économie solidaire peut-elle être feministe? Homo oeconomicus, mulher solidaria. Paris: Editions L'Harmattan. 